\title{
¿UN ASUNTO DE ESTADO? USOS PÚBLICOS DE LA MEMORIA LITERARIA ${ }^{1}$
}

\section{AN AFFAIR OF STATE? PUBLIC USES OF LITERARY MEMORY}

\author{
María do Cebreiro RÁBADE VILLAR \\ Universidade de Santiago de Compostela \\ m.rabade@usc.es
}

\begin{abstract}
Resumen: El artículo trata de examinar críticamente el papel de las instituciones públicas en la gestión de la memoria de ciertos escritores considerados canónicos y, por lo tanto, objeto, en mayor o menor medida, de los intereses de distintas instancias de carácter público y/o estatal. En concreto, se examinarán los problemas teóricos y prácticos que rodean la gestión de las tumbas de los poetas, así como las políticas culturales a las que esta cuestión ha dado (o no) lugar. Los casos de Miguel de Cervantes, Rosalía de Castro y Federico García Lorca serán tomados como campo de pruebas para averiguar en qué medida el Estado delega o no en otras entidades - y en este último caso, cuáles - el patrimonio literario, entendido también, por su relación con el derecho de filiación, la propiedad intelectual o la muerte, como un patrimonio de naturaleza biopolítica que demanda una mayor reflexión colectiva y responsabilidad en términos de su uso público.
\end{abstract}

Palabras clave: literatura y muerte, memoria literaria, Estado, patrimonio cultural.

Abstract: The article aims at explaining critically the role of public institutions in managing the memory of so-called "canonic" writers and thus of interest, to a greater or lesser extent, to several institutions. More specifically, it will examine the theoretical and practical problems around public management of the tombs of poets, as well as the cultural policies that have arisen (or not) in relation to this. The cases of Miguel de Cervantes, Rosalía de Castro and Federico García Lorca will be taken as testing ground to find out to what extent the State delegates literary heritage to other entities - and in that case, which ones - considered also, in relation to parentage law, copyright or death, as a heritage of biopolitical nature that demands a deeper collective reflection and responsibility in terms of public use.

Keywords: literature and death, literary memory, State, cultural heritage.

\footnotetext{
${ }^{1}$ Artículo vinculado al proyecto de investigación "Cartografías del afecto y usos públicos de la memoria: un análisis geoespacial de la obra de Rosalia de Castro” (FFI2017-82742-P), financiado por el MINECO (Gobierno de España).
} 
$\mathrm{Q}$ ué debe hacer el Estado cuando mueren los poetas? ¿Debe dejarlos descansar literalmente en paz o, por el contrario, es responsable de reavivar su memoria por medio de los dispositivos más o menos sofisticados del recuerdo que articulan la economía política de las conmemoraciones públicas? La cuestión se vuelve todavía más compleja en el caso de todas aquellas tumbas heredadas a menudo como problema histórico mucho tiempo después de haber sido construidas: sepulcros que en algunos casos fueron trasladados, o cuyo emplazamiento el paso del tiempo ha borrado o vuelto incierto. En este contexto, las tumbas de los poetas —que, como veremos a continuación, no están desprovistas de inesperadas conexiones con la memoria del franquismopueden operar como campo de pruebas para calibrar la eficacia teórica y política de la noción de memoria literaria. Con el término de memoria literaria buscamos probar y, en su caso, reconocer la pertinencia de una categoría analítica de contornos algo más precisos que la de memoria cultural, cuyo uso en la bibliografía global se ha vuelto casi inflacionario ${ }^{2}$, pero con la que guarda algo más que una relación de vecindad. La memoria literaria puede ser entendida, en efecto, como una modulación específica de la memoria colectiva — por referirnos ahora al seminal trabajo de Halbwachs (1992) estrechamente relacionada con la forja de modelos, categorías y formas de representación del vínculo entre la literatura, la vida y la muerte. Claro está que el análisis aquí propuesto no es sino un primerísimo paso en este rastreo; las posibilidades de la noción serán por ahora someramente presentadas a partir de tres estudios de caso: Rosalía de Castro, Federico García Lorca y Miguel de Cervantes.

A medio o largo plazo, un programa como el bosquejado permitiría precisar en qué medida el recuerdo de la vida y de la muerte de los poetas constituye o no un espacio autónomo de producción de formas de memoria y de instancias de producción de ideas sobre la posteridad de determinados cuerpos y legados. El desafío pasaría, en otras palabras, por esclarecer cómo la herencia cultural vinculada a la memoria de la vida y de la muerte de ciertos escritores puede echar luz sobre el funcionamiento de esa fábrica de tumbas generada por la modernidad ${ }^{3}$, una poética sin duda compleja

\footnotetext{
${ }^{2}$ En el Estado Español el término que, hasta ahora, ha permitido vertebrar un diálogo social y académico más pujante sobre los usos públicos del pasado es el de memoria histórica, susceptible asimismo de revisión crítica y, eventualmente, de ampliación. Cabe recordar, en todo caso, que los largos años de discusión en torno al alcance del término no han permitido cancelar en la práctica los problemas derivados de la apertura de las fosas de la Guerra Civil, como lo demuestran a las claras las dificultades relacionadas con la implementación legal y efectiva de las políticas del reconocimiento de las víctimas. Que el análisis crítico de este conflicto desde el punto de vista de los estudios culturales haya sido emprendido, en primera instancia, desde fuera de las fronteras del Estado (Resina 2000, Labanyi 2002, Labanyi 2007) no deja de ser un síntoma muy elocuente. En el ámbito académico español del último decenio, resultaría insoslayable reconocer que los debates en torno a la memoria y posmemoria de la Guerra Civil han sido anticipados, pero también acompañados y seguidos, de un copioso corpus de literatura, generalmente narrativa. Este corpus ha dado lugar a su vez a un todavía más copioso volumen de bibliografía, que concede privilegio en el análisis a las novelas sobre la memoria histórica, fundamentalmente de la Guerra Civil, en detrimento de los demás mecanismos de representación e invención de las dinámicas de recuerdo y olvido (por ejemplo, entre otros, los de la poesía).

${ }^{3}$ De modo tentativo, podemos aventurar la hipótesis de que a menudo la modernidad cultural implicó una transformación de los escritores en una suerte de santos laicos, provistos de un aura ya no vinculada a la ejemplaridad moral sino, con frecuencia, al malditismo o a la excentricidad: piénsese, para la literatura hispánica y latinoamericana, en el caso de la
} 
en la que resulta fundamental atender a la dialéctica entre recuerdo y olvido, presencia y ausencia o desplazamiento y radicación. Pero hablamos también de eficacia política porque este juego de cuestiones estaría llamado a cuestionar algunos de los usos actualmente vigentes en la gestión institucional de la literatura, en un tiempo en el que no queda claro cuál es, o cuál debería de ser, su papel social. A esta luz, lugares llegados del pasado como los sepulcros, solo en apariencia alejados de las políticas del presente, pueden ser entendidos como una poderosa caja de resonancia en la que retumban los conflictos y traumas de la historia política y cultural.

\section{Rosalía, Cervantes, Lorca: lugares de memoria, de desplazamiento y de vacío}

En lo que sigue, trataré de avanzar algunas hipótesis de trabajo sobre la cuestión planteada, a partir de los casos de estudio enunciados. Entendemos que su valor para un análisis como el propuesto viene dado, fundamentalmente, por el hecho de que los tres encarnan problemas de gestión de la memoria cultural bien diferenciados entre sí, pero a su vez cosidos por algunos de sus costados. Todos ellos constituyen, además, un convite a tomar en consideración distintas instancias culturales y no culturales, públicas y privadas, laicas y religiosas en el análisis entre literatura y Estado. A menudo se olvida que en las actuales sociedades mediáticas y de consumo, el análisis literario — generalmente sujeto durante años, en las aproximaciones sociológicas, a la metodología de Pierre Bourdieu (1995) , no puede reducirse al estudio de las interacciones entre el poder político, el económico y el cultural, toda vez que estas mismas esferas están siendo sujetas a reestructuraciones muy profundas. Pensemos, sin ir más lejos, en la progresiva conversión del patrimonio cultural en bien de consumo turístico, un fenómeno desde luego no reciente, pero muy intensificado desde inicios del siglo XXI, con las consecuencias que ello entraña para la parque-tematización de las ciudades históricas. También en el modo en el que el denominado periodismo cultural configura una agenda cada vez más confluyente con las guías del ocio y en la que resulta fácil constatar la sujeción de la información a la política de las efemérides ${ }^{4}$. En un momento en el que la utilidad de la literatura no es algo que pueda, ni acaso deba, darse por hecho, merece especial atención el lugar que debe concederse al patrimonio literario en la sociedad y, muy particularmente, a quién corresponde reconocerlo, custodiarlo y/o inventariarlo, asignarle valor y, por último pero no en último lugar, analizarlo.

La necesidad de tener en cuenta las distintas instancias de reapropiación de los cuerpos se percibe de modo especialmente nítido en los casos de Cervantes y Rosalía, debido a la propiedad eclesiástica de los lugares en los que están actualmente enterrados: la capilla de la Visitación, en el Convento de Santo Domingo de Bonaval en Santiago de Compostela y el convento de las Trinitarias, en el madrileño

antología Los raros, de Rubén Darío, publicada en el año 1896. Estas figuras imantadas de la modernidad surgen, precisamente, como consecuencia del proceso de desacralización de la producción artística que Benjamin identificaba con la pérdida del aura. A esta luz, no es casual que las peregrinaciones antiguas a ciertos lugares sagrados (incluyendo, en muchas tradiciones, las tumbas de los santos) hayan sido progresivamente reemplazadas, en las culturas masivas, por el tour turístico a las tumbas de los escritores o, en formas más extremas del moderno culto a la muerte, por el necroturismo. ${ }^{4}$ Ello tiene repercusiones obvias en términos de la metodología de la investigación, debido a la necesidad de atender, como fuentes de atención insoslayable, a las crónicas periodísticas que dan cuenta del impacto de determinados acontecimientos (aniversarios de los escritores u operaciones de búsqueda y/o enterramiento de los cuerpos, en el caso de este artículo) en el espacio público. 
Barrio de las letras. No se trata tan solo de que los lugares de emplazamiento de los cuerpos sean nítidamente religiosos; también los ritos de enterramiento han participado, como veremos en los dos casos, del ritual católico. Concretamente, las circunstancias que han rodeado la reciente exhumación de Cervantes obligan a tener en cuenta el papel de la Iglesia como institución todavía muy presente en el espacio público y en la gestión del patrimonio cultural, a pesar de que constitucionalmente el Estado español se haya definido como un Estado laico. Desde el punto de vista de una crítica a los usos institucionales de los cuerpos muertos, no deja de ser notable las atribuciones del poder eclesiástico a la hora de condicionar, o incluso de pautar, el acceso a un patrimonio en el que el Estado, los gobiernos autonómicos o los municipales pueden haber realizado inversiones sustanciales. De este modo, aquellas tumbas que, desde el punto de vista del espacio público, bien podrían ser visualizadas como lugares de memoria (Nora 1986), se convierten, de facto, en lugares de peregrinación. A pesar del gasto público aprobado para la exhumación forense por parte del Ayuntamiento de Madrid, las visitas a la tumba de Cervantes están sujetas al horario de culto, y el Panteón de Gallegos Ilustres, "cementerio laico del galleguismo" (Salgado 2010) ha protagonizado un litigio entre los poderes civil y eclesiástico que llegó a mantener la capilla cerrada al público durante meses.

Un sugerente punto de sutura en los tres casos de estudio es el que apunta a las incógnitas que rodean al nacimiento y a la muerte de los poetas, momentos que en los entierros aparecen extrañamente vinculados. El cuerpo de Cervantes es, como el de Lorca, un enigma. A diferencia de éste, en aquél ha sido posible determinar un lugar y localizar unos vestigios. Sin embargo, a pesar de las sofisticadas técnicas de la topografía y de la medicina forense, tal vez nunca será posible asegurar del todo su identidad. Si consideramos conjuntamente los casos de Cervantes y Rosalía, tenemos, por una parte, el cuerpo del soldado manco, objeto de una laboriosa exhumación en la que no es posible despejar todos los interrogantes $y$, por la otra, el cuerpo de una hija ilegítima, cuya paternidad todavía es disputada en las dos principales líneas interpretativas de los estudios rosalianos ${ }^{5}$. Es sabido que el tiempo dificulta notablemente los trabajos de identificación de los cuerpos, incluso en casos más cercanos como las fosas de la Guerra Civil, pero esta consideración no ha sido óbice para que el Ayuntamiento de Madrid se implicase activamente en la exhumación de Cervantes. Se trata, por lo demás, de una muestra palpable de que en la sociedad actual de consumo la supervivencia del patrimonio cultural pasa por su espectacularización, una tendencia en la que los medios de comunicación juegan, como es sabido, un destacado papel. A esta luz, y teniendo en cuenta su notable centralidad en el campo cultural gallego, podría incluso sorprender que hasta ahora nadie haya defendido para Rosalía de Castro una nueva exhumación que permita, por medio de la prueba de ADN,

\footnotetext{
${ }^{5}$ La orientación dominante la hace hija del sacerdote Martínez Viojo, cuestión que, por comprensibles razones históricas, no ha podido ser probada. Sin embargo, el meritorio trabajo de investigación de María Victoria Álvarez Ruiz de Ojeda $(1997,1999,2000)$ ha hecho posible acceder a documentación sobre la relación entre Rosalía de Castro y su supuesto padre, e incluso al testamento de este. Precisamente las pesquisas de esta autora a propósito del fuerte vínculo entre la autora y su familia materna han sustentado la segunda tradición interpretativa que, a pesar de su carácter hoy en día minoritario, es defendida por autores de tanto predicamento en el campo cultural gallego como el escritor y filólogo Xosé Luis Méndez Ferrín (2007a, 2007b). Esta segunda tradición llega a apuntar incluso a la sombra del incesto, lo que permitiría afirmar -en línea con el énfasis de su viudo Murguía en la hidalguía de los Castro- una genealogía matrilineal de la autora gallega. Para la polémica puede consultarse, además, el artículo de Doval (2014), que toma partido por la primera tradición, así como la reseña de Rodríguez (2018) a la última biografía disponible sobre la autora (Lama 2017).
} 
determinar de acuerdo con el método científico la filiación con los descendientes de Martínez Viojo, toda vez que a la muerte de Gala, su última hija, no hay descendencia directa de la familia MurguíaCastro. Pero como veremos, en el caso de Rosalía de Castro las instancias de legitimación de su obra y de su figura literaria no suelen actuar de acuerdo con la lógica de la evidencia empírica y de la comprobación y siguen más sujetas a lo que, en su biografía del historiador Manuel Murguía, marido de la escritora gallega, Barreiro Fernández ha denominado "derivación del mito [de Rosalía] hacia el culto [a Rosalía]" (2013: 458).

La entrada de un saber médico-forense en la gestión necropolítica permite emparentar también los casos de Cervantes y de Lorca por un ángulo solo en apariencia incidental. El antropólogo forense Francisco Etxeberria Gabilondo, investigador integrado en el equipo multidisciplinar encargado de la exhumación de los restos de Cervantes en las Trinitarias, es un notable activista a favor de los derechos relacionados con la memoria de la Guerra Civil española, y miembro eminente de la Asociación para la Recuperación de la Memoria Histórica (ARMH). No es casual, en este contexto, que haya participado también en el complejo proceso de recuperación de los restos de Lorca, un proceso en exceso condicionado por los avatares que han rodeado la implantación de la Ley de la Memoria Histórica, y con no pocas interferencias entre la gestión del gobierno autonómico (la Junta de Andalucía, en este caso) y el Estado. La particular (y a menudo en disputa) estructura territorial del Estado español, y las tensiones entre el centro y las periferias a las que esta periódicamente da lugar, obligan a tener presente distintas escalas en este análisis: la autonómica desde luego, pero también, como veremos, la municipal. A ello cabe sumar la entrada en juego de entidades privadas y/o semiprivadas — en la medida en que a menudo reciben subvenciones públicas — entre las que juegan un papel destacado las Fundaciones o Patronatos legatarios de la memoria de los escritores. Esta multiplicidad de agencias podría hacer pensar en fenómenos de transferencia, cuando no de incomparecencia o incluso dilución, del Estado en estos asuntos. Sin embargo, más bien parece que el vínculo entre la literatura autónoma y el Estado soberano, proceso constitutivo de la modernidad, es el que garantiza, formalmente o de facto, la existencia o exigencia de un culto laico a ciertos escritores que parecen llamados a sobrellevar una memoria no reductible a los límites de su biografía ${ }^{6}$.

\section{El "error de traslación" y el culto rosaliano}

Empecemos por el caso de Rosalía de Castro, una autora capaz de poner de acuerdo a instituciones autonómicas y estatales como la Real Academia Gallega, el Consello da Cultura Galega, la Fundación Rosalía de Castro o el Ministerio de Fomento, pero también a representantes políticos de orientaciones tan dispares como Martiño Noriega — alcalde de la ciudad de Santiago de Compostela,

\footnotetext{
${ }^{6}$ Soy deudora, en este pasaje en particular, y a lo largo del artículo, de las lecturas y reflexiones surgidas al hilo del productivo seminario de investigación que, bajo el título "Propuestas para el estudio comparado de literatura y Estado" dictó el profesor de la UBA Marcelo Topuzian en la Universidad de Santiago de Compostela, los días 15 y 16 de marzo de 2018, así como de las conversaciones con el profesor Fernando Cabo Aseguinolaza, al hilo de la gestión biopolítica de la memoria literaria de Rosalía de Castro. Un tratamiento más profuso de los problemas señalados en el tratamiento de las tumbas de los escritores españoles será objeto de un libro actualmente en curso, coordinado junto con la profesora Margarita García Candeira.
} 
actualmente en manos de Compostela Aberta, candidatura vinculada al movimiento municipalista de las Mareas - y Alberto Núñez Feijoo, político del Partido Popular que preside la Xunta de Galicia. Eso es lo que sucedió cuando a principios de 2017 se tomó de forma unánime la decisión de rebautizar el aeropuerto compostelano de Lavacolla con el nombre de Rosalía de Castro, iniciativa aprobada en pleno del ayuntamiento de Santiago, a la que el día 8 del mes de febrero se adhirió el parlamento gallego, y que muy poco después fue ratificada por AENA.

La decisión llegaba poco tiempo después de otros dos hechos con el que esta operación de dar un nombre guarda no pocas relaciones ${ }^{7}$. El primero es la elección de la efigie de Rosalía de Castro, acompañada del pie "Spanish author", por parte de la compañía Norwegian Airlines, que la eligió como imagen de uno de los 85 aviones de su flota destinados a conmemorar a personajes históricos, artísticos y literarios de los países nórdicos, el Reino Unido y España. El segundo es su aparición, como doodle del buscador de Google, 9 de febrero de 2017; es decir, tan solo un día después del anuncio de que el topónimo de Lavacolla sería desplazado por el nombre de Rosalía de Castro. No era la primera vez. Tan solo dos años antes, la empresa de Sillicon Valley, acaso por mediación de instancias como el Consello da Cultura Galega (el principal responsable de la acción exterior en el ámbito cultural gallego), ya había tendido un puente con la memoria rosaliana. Sucedió el 24 de febrero de 2015, cuando en la vida literaria de la comunidad estaban todavía recientes las conmemoraciones institucionales por el sesquicentenario del libro Cantares gallegos (2013), que la historiografía interpreta como aurora y cima del Rexurdimento literario. Si desde 2006 el gobierno bipartito de la Xunta de Galicia, en manos entonces del PSOE y del BNG, había impulsado ya una política de efemérides alrededor de la escritora, a lo largo de aquel año 2013 la tendencia creció exponencialmente, y se sucedieron los actos de homenaje a la que es sin duda la autora más canonizada de la historia de la literatura gallega. Entre otras pruebas, podemos referirnos al Congreso celebrado en el Consello da Cultura Galega, en coorganización con la Universidad de Santiago de Compostela - que en buena medida continuaba el I Congreso Internacional sobre Rosalía de Castro no seu tempo, con el que las mismas entidades habían conmemorado en el año 1885 el centenario de la muerte de la escritora- y a numerosas iniciativas bibliográficas y discográficas promovidas por empresas editoriales como Edicións Xerais de Galicia o Editorial Galaxia. Pero el verdadero arranque de aquel año rosaliano había tenido lugar cuando, en diciembre de 2012, el presidente de la Xunta de Galicia eligió la Casa da Matanza, lugar donde Rosalía de Castro murió y sede de la Fundación que lleva su nombre, como emplazamiento para su discurso de fin de año. A pesar de lo deliberado de la elección,

\footnotetext{
${ }^{7}$ Una de las pocas voces críticas ante esta iniciativa por parte de los integrantes de la sociedad civil era la del investigador y escritor Mario Regueira (2017), que en su blog O porto dos escravos se detenía, no por casualidad, en la relación entre la apropiación del nombre de la autora y el uso público de un ciclo narrativo de Walter Scott, escritor, por cierto, muy admirado por Rosalía: "No me opongo, aún así, a que Rosalía de Castro dé nombre al aeropuerto de Compostela, simplemente me pregunto si fue un movimiento inteligente. El principal argumento que escucho dice que Rosalía va a dar la bienvenida a miles de visitantes de todo el mundo. En mi última visita a Edimburgo, llegando a la estación de tren de Waverley fui consciente por primera vez de que estaba bautizada en honor de una novela (y ciclo narrativo) de Walter Scott. Las citas del autor, que tiene en la ciudad el mayor monumento nunca dedicado a un escritor, daban la bienvenida a quien viajaba sin que nadie tuviera la idea genial de marcarlo en un epónimo. En cierto sentido, la relación entre Edimburgo y su hijo Walter Scott es tan intensa que ciertas cosas están de más. ¿Será que Compostela fracasó a la hora de marcar su relación con la poeta romántica hasta el punto de tener que estampar su nombre en la puerta de entrada?”.
} 
Núñez Feijoo confundió en sus palabras el lugar de la muerte de la poeta con el lugar de nacimiento, error solo comparable al cometido por él mismo cuando en mayo de 2014, en el marco de una entrevista a V Televisión, al hilo de una pregunta sobre el Día de las Letras Galegas, rebautizó el libro Cantares gallegos (cuya efeméride, tan solo un año antes, había forzado el emplazamiento del discurso en la Casa da Matanza) con el de Poemas gallegos.

El aluvión de reconocimientos, celebraciones y efemérides que en los últimos diez años han venido rodeando en Galicia la obra de Rosalía no es extraña, como hemos visto, a la agenda cultural de las sociedades contemporáneas, pero el caso rosaliano ofrece no pocas particularidades. Una es la ubicua y poderosa iconicidad de la imagen de la escritora, que muestran a las claras ejemplos como los señalados, y que no es posible desvincular de su género dada la importancia que en la configuración de una imagen autorial, tanto en el pasado como en el presente, ha tenido el cuerpo de las mujeres (Clúa 2016). En el caso de Rosalía de Castro, esta intensa iconicidad ha dado lugar incluso a iniciativas de comercialización como la de la warholizada camiseta de la empresa Rei Zintolo, años después de que la cara de la autora gallega apareciese estampada en los billetes de quinientas pesetas de la Real Fábrica de Moneda y Timbre - este último, sin duda, un poderoso indicio del modo en que el Estado asume como propios no solo el legado, sino también la efigie de los escritores. Más recientemente, el Consello da Cultura Galega tendía sin duda un guiño a la emblemática Rosalía vista por Warhol cuando, para crear la imagen del mencionado Congreso Internacional, transformaba un retrato histórico de la autora gallega por medio del ingenioso (pero, en otro sentido, literalmente impropio) recurso de despeinarla. Es el proceso de santificación de Rosalía, cuyo origen exploraremos en lo que sigue, lo que explica que la imagen de la escritora se mueva, de modo dialéctico, entre el tipo y el antitipo. Esto es así hasta el punto de que la necesidad de "desacralizar" a la autora se ha convertido, en el discurso cultural gallego, en un tópico casi tan presente como el imperativo de su sacralización, sin duda más subliminal en la actualidad que en el pasado pero, como veremos, en absoluto desactivado.

Regresemos ahora a los doodles de Rosalía en Google para estudiar, siquiera brevemente, la dimensión imaginaria de su tratamiento en internet. Frente al más sobrio de 2017, el doodle de 2015 es una versión ilustrada de un conocido retrato de juventud de la autora. Al fondo, una imagen bucólica del ondulante y verde paisaje cantado por la escritora, con el escudo del Antiguo Reino de Galicia sobreimpreso en la primera "o" de la palabra "Google". También en segundo plano, pueden leerse los versos iniciales del cantar "Adiós ríos adiós fontes", sin duda el poema más recordado de Rosalía y acaso el más presente, todavía hoy, en las escuelas gallegas. El texto asociado a aquella imagen de 2015 era un mensaje de cumpleaños: aquel día se cumplían, en efecto, 178 años del nacimiento de la escritora. En tan solo tres líneas, el mensaje conjugaba una de las múltiples tensiones que atraviesan la obra rosaliana: el compromiso con Galicia y con su idioma, que hacen de ella el verdadero centro del canon literario gallego, y su dedicación a la literatura castellana, que, de acuerdo con la definición tradicional de las literaturas nacionales, fundamentadas en la contigüidad natural entre nación, literatura y Estado, la convierten también en una escritora española: "Set against the Galician landscape, our doodle features a portrait of Spanish writer and poet Rosalía de Castro for her 178th 
birthday". "Spanish writer" que, como el "Spanish author" de Norwegian Airlines constituye un caso emblemático de nacionalismo banal (Billig 1995). Por más que el canon de la literatura autonómica reconozca a Rosalía como la autora del primer poemario en lengua gallega, y por más que en el contexto de la literatura española siga teniendo una posición "desajustada" (Cabo 2011: 19), en el ámbito internacional es reconocida como "Spanish Author", incluso por instancias no estatalizadas aunque sin duda afectadas por las políticas estatales - como Google.

Sirva este carácter aural del cuerpo de la poeta, asentado en una suerte de fractalidad imaginaria - debido, entre otros factores, a su posición intersticial entre las literaturas española y gallega - para brevemente entrar en los avatares de su traslado del cementerio padronés de Adina al Panteón de Gallegos Ilustres, donde todavía reposa. Este traslado, que el historiador Barreiro ha denominado "error de traslación" es el verdadero comienzo del proceso de santificación de la escritora y, no por casualidad, fue promovido por la comunidad emigrante en América, concretamente en La Habana, que había ya financiado su libro Follas novas (1881). Vale la pena traer a este contexto uno de los documentos cruciales ligados a la biografía de Rosalía de Castro y que, pese a su indudable interés, apenas ha sido objeto hasta ahora de ningún comentario exhaustivo, más que para esclarecer, de modo por lo demás muy oportuno, sus incongruencias en relación con la verdad histórica (Rodríguez 2011: 548 y ss). No es un texto sobre su vida sino sobre su muerte. El texto por definición sobre una muerte: un acta notarial que da cuenta de la exhumación del cuerpo, que había sido enterrado en el padronés cementerio de Adina, y posterior traslado en tren, desde la estación de Padrón a la estación de Cornes, en Conxo, donde había nacido, y posterior enterramiento en la capilla de la Visitación del Panteón de Gallegos Ilustres, sita en el Convento de Santo Domingos de Bonaval en la ciudad de Santiago de Compostela ${ }^{8}$.

Este documento, de extraordinario interés, fue publicado en un número especial que el periódico La Patria Gallega dedicó el 30 de mayo de 1891 al traslado, bajo el título "Acta notarial levantada en el momento de la inhumación de los restos de Rosalía de Castro" (pp. 14-16). De extraordinario interés por varios conceptos, pues brinda un soporte sustancial a la posibilidad de un análisis político y sociológico: por él desfilan la Universidad, la Banca, el Ejército, la Iglesia e instituciones políticas y culturales como la Sociedad Económica de Amigos del País o la Asociación Regionalista Gallega, entidad, esta última, que según investigadores de orientaciones tan distantes como las de Fernández (2011) o Barreiro (2012), acabaría capitalizando el acto. En el traslado del cuerpo desde la estación del ferrocarril al cementerio no solo participaron todos los estamentos de la sociedad civil y religiosa de la sociedad compostelana sino que, a juzgar tanto por el acta notarial como por las crónicas de la época, el conjunto de la ciudad se volcó en el homenaje. El acta notarial, que cumple con todos los requisito de la retórica epidíctica, tiene además algo de reseña literaria (emprende, de modo sumario, una valoración de los libros de la trayectoria rosaliana que juzga más relevantes) y reafirma de modo

\footnotetext{
${ }^{8}$ Significativamente, Rodríguez exhuma un texto del 25 de mayo de 1891, en el que el periódico pontevedrés $L a$ Correspondencia gallega compara el traslado de los restos de Rosalía desde Padrón a Cornes con el viaje post-mortem a Cracovia del poeta polaco Mickiewitz (Rodríguez 2011: 538). La vida política de los cuerpos muertos, formulado precisamente a propósito de las culturas del Este europeo, constituye el objeto de la aproximación fundamental de Verdery (1999) a este problema.
} 
inequívoco el papel que Rosalía de Castro había empezado a desempeñar en Galicia como santa cultural. Un indicio claro de ello es el texto de la inscripción elegida para el arco del monumento funerario diseñado por el escultor Jesús Landeira (1891: 15), quien años más tarde sería asimismo el artífice de la célebre estatua de la escritora en la Alameda de Santiago de Compostela:

D.O.M.

PRA ETERNA MEMORIA

GALICIA

FIXO FACER POR SVSCRICIÓN NACIONAL ESTE MOIMENTO

ONDE DESCANSA NA PAZ DO SEÑOR

A QVE FOI GRORIA DA SVA PATRIA

SEÑORA DOÑA ROSALÍA CASTRO DE MURGVÍA

FINOV EN IRIA NO 15 DE JVLIO

DO ANO DE 1885

DOU COMEZO A SVSCRICIÓN

A COLONIA GALLEGA EN CVBA,

PO-LOS COIDADOS DA SOCIEDADE ECONÓMICA

DE SANTIAGO

DOVSELLE CIMA

Jesús Landeira fecit Compostellae anno 1891

Pero es el epígrafe del acta notarial titulado "Narración” el que confirma de modo inequívoco su participación en la tópica del cuerpo incorrupto de los santos. Sorprende, a este respecto, que un notario dé fe de que al abrir la tapa del sepulcro padronés el cuerpo se encontrase "apenas desfigurado, con la ropa que le sirve de mortaja bastante conservada, advirtiéndose sobre el pecho de la gloriosa muerta un ramo de pensamientos, ligeramente decolorados y cual si estuviesen recientemente cortados, que la piadosa mano de su cariñosa hija, la señorita Alejandra M. Murguía Castro, había en él puesto cuando se [le] dio cristiana sepultura" (1891: 16).

Cierto es que la dinámica de efemérides descritas al inicio de este epígrafe confirman que la idea del cuerpo incorrupto de la Santiña - por ese nombre, que figura incluso en fuentes historiográficas, fue llamada Rosalía de Castro hasta bien entrado el siglo XX — ha dado paso a mecanismos no menos sugerentes desde el punto de vista de la relación entre literatura, Estado y naciones sin Estado ${ }^{9}$. En algunos de ellos se perciben todavía residuos de la sacralización aural de la poeta muerta, como en la exhibición museística de un rizo de la autora, en una publicitada cesión de la Diputación de A Coruña a la Fundación Rosalía de Castro ${ }^{10}$. Todo ello parece confirmar la conversión de un determinado legado

\footnotetext{
${ }^{9}$ Tal es el punto de partida de un proyecto de investigación internacional titulado Cultural Saints in Europe, cuyos objetivos y producción científica asociada pueden verse en la página http://cultural-saints.zrc-sazu.si/en/, que incluye un cuestionario sobre Rosalía de Castro elaborado por el ya mencionado proyecto de investigación de la USC. Los postulados del proyecto en torno al papel de los santos culturales en las naciones europeas, con particular atención a las formaciones no estatales, ha dado lugar a publicaciones como National Poets, Cultural Saints: Canonization and Commemorative Cults of Writers in Europe (Dovic-Hegelson 2016).

${ }^{10}$ Publicitado en la página web de la Fundación el mes de julio de 2017. Sorprendentemente, al cabello de Rosalía se le brinda el mismo tratamiento documental que a los tres cuadros de Ovidio, hijo del matrimonio Murguía-Castro: http://rosalia.gal/tres-novos-cadros-de-ovidio-e-un-guecho-de-cabelo-de-rosalia-para-a-casa/ (última consulta, 25-52018).
} 
literario en bien de consumo cultural, de acuerdo con una alianza entre capitalismo y Estado que puede afectar tanto al proceso de museificación de ciertas reliquias como a la transformación de un itinerario de peregrinación articulado en torno a determinados lugares biográficos — la denominada Ruta Rosaliana $^{11}$ — en una serie de rutas turísticas, algunas de las cuales han sido recientemente presentadas en FITUR (López 2018).

Pero acaso la prueba más palpable de lo dicho sea una de las últimas operaciones de márketing cultural por medio de las cuales la Fundación Rosalía de Castro trataba de visibilizar socialmente la figura de la escritora a partir de una actualización cuando menos libre de su memoria literaria. Nos referimos al denominado "caldo de gloria", operación gastropolítica (Labrador Méndez 2014) concebida para celebrar la efeméride de su nacimiento, contexto donde empezó a cobrar fuerza el mantra cultural "Rosalía é de todos". Precisamente así era como titulaba el periódico La opinión un reportaje sobre el aniversario del nacimiento de la autora, en donde el célebre escritor Xosé Luís Méndez Ferrín encarecía la contribución de la iniciativa a la recuperación del recetario tradicional gallego: "O caldo tradicional estase perdendo, agora faise sopa. O caldo de unto, patacas e feixóns é do que fala Rosalía" (González Liste 2017), momento en que la periodista apostilla: "Ferrín (...) salienta que neses versos está o 'espírito' dela, a súa solidariedade cos pobres en xeral, 'o seu sentimento de clase que se expresa nese caldiño e nesa choza'" (González Liste 2017) ${ }^{12}$. El contexto del comentario es el poema "Miña casiña, meu lar", una de las más celebradas glosas de los Cantares, que cuenta la historia de una mujer que pide por los caminos para poder comer, con tan poca fortuna que, al final del día, no tiene más remedio que hacer un pobre caldo con los pocos alimentos que quedan en su casa. Bien lejos de la reivindicación de clase con la que soñaba Ferrín, la campaña del “caldo de gloria” significó, en la práctica, la traducción cultural de un poema en receta, y la conversión de un plato del hambre a un producto gourmet. Desde la página web de la Fundación, se incitaba a los establecimientos hosteleros y particulares se uniesen a la celebración haciendo uso, en las redes sociales, de los hagstags \#CaldodeGloria y \#DíadeRosalía ${ }^{13}$. El "caldo de gloria" sellaba de modo ejemplar uno de los últimos ejercicios de apropiación cultural de la memoria de Rosalía de Castro, y lo hacía, en su segundo año de vida, apoyado por una larga lista de restaurantes, por otras entidades

\footnotetext{
${ }^{11}$ Las tentativas de renovación de la denominada Ruta rosaliana han experimentado en los últimos meses un más que notable repunte. Sin contar con otras iniciativas precedentes, promovidas por entidades como la Asociación de Escritores en Lingua Galega, o con las vinculadas a la memoria de otros escritores como Camilo José Cela (accesible en la página de la Fundación homónima), habría que contar con las organizadas por ayuntamientos como el de Ames, que contó con la presencia de la especialista María López Sández, y cuyo principal objetivo es atraer el interés turístico por los parajes vinculados a la vida de la autora. El conjunto de actividades aparece recogido en la página web del ayuntamiento: http://www.concellodeames.gal/nova.php?idioma=gl\&noticia=16230\&sec=32 (última consulta, 25-5-2018). Para una genealogía crítica de los itinerarios en torno a la vida y la obra de Rosalía de Castro, véase Fuentes Ríos (2018).

${ }^{12}$ Otros de los comentarios de Ferrín admiten ser leídos como preparación de la cesión del rizo de la autora por parte de la Diputación: "Ferrín recorda que quedouse sempre coa (sic) protagonista da novela El caballero de las botas azules e chamáralle a atención porque sempre levaba no medio da frente un rizo, aparentemente por descuido. 'Anos máis tarde dinme de conta de que Rosalía aparece na maioría dos seus retratos tamén con ese rizo e, polo tanto, pensaba nela cando escribiu a ese personaxe"" (González Liste 2017). Es interesante que la periodista o el entrevistado atribuyan una identidad femenina al andrógino protagonista de la novela, aspecto que refuerza la lectura biografista de la caracterización física del personaje.

${ }^{13}$ Véase http://rosalia.gal/causes/caldo-de-gloria/ (última consulta, 25-5-2018).
} 
privadas como el ámbito cultural de El Corte Inglés y públicas como los ayuntamientos de Ames, Padrón y Brión, aliados asimismo en la ya mencionada ruta presentada en FITUR.

Tal y como estamos viendo, el culto a Rosalía de Castro sigue vivo: más mediado que antaño por las instancias de consumo cultural (a la cabeza, la gastronomía y el turismo), pero siempre en alianza con los intereses políticos y a menudo al servicio del estereotipo religioso de una mater dolorosa que se sacrifica por su país, o que es sacrificada por él. La eficacia retórica de la operación del "caldo de gloria", de cuya excelente acogida se hicieron eco varios informativos nacionales, se sustentaba en la pervivencia, en el imaginario popular gallego, de una imagen de la propia Rosalía como labradora y hasta como mendicante. La campaña alentaba de este modo una identificación, sin duda socialmente activa, entre la instancia enunciadora del poema y determinadas proyecciones biográficas cuestionables a la luz del conocimiento hoy disponible sobre la ascendencia hidalga de la autora (Barreiro 2012, Lama 2017). Resulta sugerente asimismo que en la campaña se invitase a leer el poema a los participantes tras la elaboración del plato, en una suerte de conversión del texto en una fórmula para bendecir la mesa.

Y es que, se asuma explícitamente o no, muchas de las actividades de gestión cultural en torno a la figura de Rosalía se nutren todavía de la santificación del dolor propia de la moral católica; imagen que, por contraste, permitió asimismo, desde la segunda mitad del siglo XX, la construcción de un antitipo irreverente, políticamente subversivo y, sobre todo en el presente, icónico en las luchas feministas. Se trata, en cualquier caso, de un antitipo reactivo, que nunca ha conseguido desactivar del todo la impronta de una tradición casi fetichista en torno a la imagen y el cuerpo de la autora, cuyo actual emplazamiento en el convento de Bonaval dio, por cierto, lugar a una tradición, "la misa de Rosalía", fundamental para el galleguismo histórico. Desde principios de siglo, esa imagen había generado una concepción redentorista y crística de Rosalía de Castro - inducida por su marido Manuel Murguía, y de la que participarían desde principios del siglo XX autores como el propio Valle-Inclán-, llamada a instaurar ese "martirologio cristiano" con el que ya en los años sesenta el historiador Carballo Calero (1963) se refería al culto que se le tributaba incluso en medios académicos.

No tan lejana de esta tópica como podría parecer, el "caldo de gloria" promueve y multiplica mediáticamente, como en el milagro de los panes y los peces, un perfil de sobras conocido: no la escritora que, en un célebre relato recogido por Murguía en su galería de retratos Los precursores (1885), denuncia el efecto del llamado "año de hambre" (1853) sobre el campesinado, sino la misma campesina que solo tiene para comer un caldo que, pese a la extrema pobreza de sus ingredientes y a la sobriedad de su elaboración, le sabe a gloria (un término presente en el poema pero también, no lo olvidemos, vinculado al léxico y a la imaginería religiosas y a la retórica de la exaltación nacional, como lo confirma el "gloria de su patria" de su sepulcro). Que el cuidado institucional de la memoria de Rosalía de Castro pase, en fin, por la construcción y difusión social de una imagen que, por varios conceptos, distorsiona el conocimiento histórico disponible en la actualidad sobre su vida y su obra es, sin duda, un hecho que merece más reflexión de la que se le ha dedicado hasta ahora. 


\section{¿Dónde está Lorca?}

Federico García Lorca comparte con Rosalía de Castro — a quien, como es sabido, dedicó uno de sus Seis poemas galegos (1935) - la suerte improbable de los poetas que, para ser nombrados públicamente, no necesitan del apellido. Esa fortuna imprime en quienes la reciben un paradójico timbre de aristocracia popular, en virtud del cual se les tutea incluso por aquellos a quienes tal vez ellos no concederían el don de la cercanía. Probablemente este sea uno de los factores que contribuyen a explicar el modo en el que el enigma de la muerte de Lorca, poeta atravesado, como Rosalía, por una cierta aura de santidad laica, ha configurado un espacio de discusión pública ${ }^{14}$. Al mismo tiempo, el suyo se trata de un caso singular en el contexto que nos ocupa, pues, en líneas generales, ni la exhumación de Rosalía de Castro ni la de Miguel de Cervantes han dado lugar a polémicas como las que han rodeado su búsqueda. Lo distintivo aquí es, sin duda, que Lorca ha sido asesinado en un contexto muy preciso y que su cuerpo, al mismo tiempo rehén y botín de un conflicto histórico no concluido - como lo demuestra, entre otros indicios, la propia vigencia del debate público que rodea su búsqueda-, no ha aparecido todavía. Como muestran, entre otros, los trabajos de María M. Delgado (2008) en torno al carácter espectral de la memoria literaria lorquiana, es la desaparición del cuerpo la que incrementa la singularidad asociada a la figura del poeta, en virtud de una operación la problemática pero insoslayable relación entre vida y obra. Esta relación ha alimentado el establecimiento de ecos casi proféticos (si no por su cualidad visionaria, sí por la posibilidad de lectura retrospectiva que abren) entre el vitalismo frustrado de la poesía lorquiana y el destino trágico del poeta $^{15}$, e incluso ha sustentado hipótesis sobre la ejecución de Lorca basadas en el problema de la propiedad de la tierra, a la luz de ciertas interpretaciones biografistas de la obra teatral La casa de Bernarda Alba (Caballero 2011, Ventura 2015).

Para comprender en detalle las operaciones, hasta ahora infructuosas, de localización del cuerpo de Lorca conviene remontarse a los años cincuenta del pasado siglo, momento en el que el historiador americano Agustín Penón, descendiente de exiliados catalanes, emprendía por primera vez una investigación en torno a su muerte, reconstruida recientemente en el documental de RTVE La maleta de Penón (2009). La hipótesis de Penón, avalada por uno de los sepultureros, situaba el cuerpo en el barranco de Víznar. Años después, con la colaboración de Manuel Castilla, de profesión banderillero

\footnotetext{
${ }^{14}$ Un espacio capaz de desatar polémicas en el ámbito académico, civil y hasta judicial, como se deduce de hechos disímiles, pero conectados entre sí por el nombre del poeta, como el pleito entre dos profesores de la Universidad de Granada (Cortés 2008), las sospechas de corrupción en algunas de las instituciones legatarias de la memoria lorquiana (Martín-Arroyo 2015) o los permisos, en ocasiones denegados por la justicia, para investigar en las fosas de la Guerra Civil (Pastoriza 2016). Cuestión, esta última, en la que han desempeñado un papel no menor las licitaciones y concesiones relacionadas con las obras públicas, aspecto que permite establecer conexiones sin duda inquietantes entre la gestión de la memoria cultural y la especulación urbanística.

${ }^{15}$ En el contexto de su crítica a la cultura de la Transición española Labrador Méndez (2016: 11-24) ha señalado el valor político de la musicación flamenca de los versos de Lorca en el disco La leyenda del tiempo. Resulta asimismo significativo que Miguel Poveda haya elegido el profético verso del poeta granadino "No me encontraron" (2018) para titular el primer single y videoclip de su inminente disco EnLorquecido.
} 
y apodado "Manolillo el Comunista", el periodista Ian Gibson (1971) situaba el olivo bajo el que Lorca habría sido enterrado en el municipio granadino de Alfacar, cerca de Fuente Grande (Aynadamar en árabe), en medio de un paisaje profundamente afectado ya por el urbanismo desarrollista de finales del régimen de Franco. El árbol constituye hoy la puerta de entrada del Parque García Lorca, monumento natural proyectado en recuerdo de las miles de víctimas de la represión en esa zona, y en donde figura un monolito con la leyenda "A la memoria de Federico García Lorca y de todas las víctimas de la Guerra Civil (1936-1939)", así como una estela funeraria que proclama "Lorca eran todos".

Pese a la innegable resistencia con la que, en principio, fueron recibidos por parte de los sectores más conservadores - basta con recordar que el primer libro que consagró al tema fue prohibido en España-, la influencia de los trabajos de Gibson ${ }^{16}$ se percibe en el eco obtenido por las sucesivas versiones de sus trabajos biográficos sobre Lorca. En un contexto relativamente proclive a las políticas del recuerdo ${ }^{17}$, y poco después del centenario del nacimiento del poeta, un grupo de arqueólogos, con el aval de la Junta de Andalucía y la Asociación para la Recuperación de la Memoria Histórica, emprendía en el año 2009 una excavación en la fosa de Alfacar, que arrojaba una conclusión negativa en relación con los restos de Lorca. En el año 2013 el barranco quedaría señalado como "Lugar de memoria histórica de Andalucía”, de acuerdo con el catálogo accesible en la página web de la Junta, y en noviembre de 2014 se abriría otra investigación, sustentada en el trabajo del periodista falangista Eduardo Molina Fajardo, que a mediados del siglo pasado había difundido ya 48 testimonios de personas relacionadas con la detención y ajusticiamiento del poeta. Un croquis brindado al periodista en 1969 por el capitán José María Nestares y su propio testimonio oral, años después, a los líderes de la investigación permitió situar el supuesto lugar del enterramiento en Peñón del Colorado, un emplazamiento situado a 400 metros del Parque García Lorca, y que había sido un antiguo campo de instrucción de la Falange.

Que el testimonio de un falangista haya servido para esclarecer la búsqueda del cuerpo más enigmático, como presencia ausente, de todos los que por aquí desfilan se trata de un claro ejemplo de lo que, de acuerdo con la teoría hegeliana de la historia, se denominaría "astucia de la razón". En efecto, el trabajo que pretende limpiar la memoria de la Falange en un asunto tan ominoso como la ejecución político-militar de un poeta ofrece al mismo tiempo sustento argumental para justificar la continuidad de una búsqueda que pretende reparar su memoria. Otro indicio inquietante de la dificultad para distinguir entre azar y necesidad en la reciente historia de España es el hecho de que la financiación destinada a los drenajes profundos para la construcción de un campo de fútbol fuese objeto de malversación de caudales públicos, lo que permitió que la tierra original del solar se mantuviese intacta. Fue ello lo que, no sin sarcasmo, permitió afirmar al historiador Miguel Caballero, que junto con el arqueólogo Javier Navarro Chueca fue el investigador principal de esta exploración: "Por una vez, la corrupción en este país sirve para algo" (en Camacho 2016b). Esta última campaña

\footnotetext{
${ }^{16}$ Para las circunstancias específicas de la muerte de Lorca, además de los trabajos de Gibson pueden consultarse los testimonios, no siempre convergentes, de Pozo (1977), Molina Fajardo (1983), Vila-San-Juan (1977), Osorio (2011) o Caballero (2011).

${ }^{17}$ Relativamente porque en 2008 "la Audiencia Nacional había paralizado la orden de exhumación de 19 fosas, dictada por el juez Baltasar Garzón, entre ellas aquella en la que se suponía que estaban los restos de García Lorca” (Pastoriza 2016).
} 
fue llevada a cabo por un equipo integrado por investigadores de Argentina, España y el Reino Unido, y recibió una ayuda de la Junta de Andalucía durante el gobierno de coalición entre Izquierda Unida y el PSOE. La falta de continuidad en las políticas de gestión de la memoria de la Guerra Civil española afectó nuevamente al proyecto, que se vio interrumpido en un momento decisivo: debido a los cambios en el terreno los investigadores se habían apartado cuarenta metros del que consideraban que era el verdadero lugar del enterramiento. En abril de 2017 los investigadores concluyeron que los restos del poeta podrían haber sido trasladados poco después de su ejecución (Rodríguez 2017). Todavía más recientemente, y tras las cuatro búsquedas infructuosas llevadas a cabo hasta el momento, la nieta de Dióscoro Galindo, el maestro republicano ajusticiado junto a Lorca, ha vuelto a solicitar un permiso a la Junta de Andalucía para proseguir las exhumaciones en Alfacar.

El interés del caso de Lorca viene dado por diversos factores. En primer lugar, porque es un lugar de conflicto histórico y biopolítico: como lo demuestran otros casos de gestión del patrimonio español como el Pazo de Meirás, propiedad de la familia de Franco, o el Valle de los Caídos ${ }^{18}$, se sitúa en el centro de una cuestión no resuelta por la democracia española, y que se reabre periódicamente a pesar de las múltiples resistencias que plantea la reapertura efectiva de las tumbas. En este sentido, la estela del parque García Lorca trata de recordar la estrecha vinculación del nombre de su nombre con la suerte de multitud de muertos reclamados y no reclamados, muertos con nombre y anónimos. Pero ese monumento no deja de recordarnos, asimismo, su imposibilidad para dar nombre a todos los cuerpos, y no únicamente al del poeta, entre todos ellos el más susceptible de ser patrimonializado por los poderes públicos. Se trata, en puridad, de una cuestión de nombre y de una cuestión de número. ¿Cuál es la cifra exacta de los muertos que hay allí, o cerca de allí? No saberlo con exactitud forma parte de la violencia del Estado, pero sin duda es también una operación violenta la reducción de un cuerpo a una cifra, como recordaba Elena Poniatowska (2018: 10) en su evocación de la matanza del 2 de octubre de 1968 en México, que dio lugar a un monumento en el que había nombres, pero no números: "Quizá nunca sepamos cuántos murieron, solo tenemos los nombres de la estela en la Plaza de las Tres Culturas. Sin embargo, resonará en nuestros oídos durante muchos años la pequeña frase explicativa de un soldado al periodista de El Día José Antonio del Campo: “Son cuerpos, señor...”.

En el monumento del Parque García Lorca, el nombre del poeta adquiere la función de representar a miles de represaliados políticos que en la memoria colectiva han quedado reducidos a una cifra más o menos exacta. La operación de restitución confirma, de algún modo, el desdibujamiento de los límites entre antroponimia y toponimia en los lugares de memoria que invocan, al mismo tiempo, una ausencia o una presencia humanas. Puede resultar esclarecedora, precisamente por sus problemas y limitaciones, la genealogía teórica del problema de nombrar. Esta es la encrucijada en la que se sitúa la tradición que, desde finales del siglo XX, vincula la teoría política y la teoría psicoanalítica ${ }^{19}$. En un capítulo significativamente

\footnotetext{
${ }^{18}$ Eduardo Ranz, el abogado que se encarga de la representación de la nieta de Galindo en la solicitud de la última exhumación en el Parque García Lorca, es el mismo que consiguió recuperar recientemente los restos de varias familias en el Valle de los Caídos. Así lo recogía el 16 de mayo de 2018 en el diario Público, bajo el titular "La Junta de Andalucía respalda la nueva iniciativa para buscar los restos de Lorca" (http://www.publico.es/politica/junta-andalucia-respaldanueva-iniciativa-buscar-restos-lorca.html, última consulta 25-5-2018).

${ }^{19}$ Como es sabido el problema se remonta a la tradición analítica. En la lógica simbólica de Frege (1998), el nombre es la operación que genera el cero y el uno a partir de la nada, mientras que para Bertrand Russell (1910) se trata de una descripción definida (dado que todo nombre tendría un contenido equivalente a una suma de rasgos descriptivos) y para Saul Kripke (1980), que parte fundamentalmente de los dos filósofos mencionados y es el principal referente teórico de Laclau en esta cuestión, de un designador rígido.
} 
titulado "Nominación y afecto", Laclau sigue de cerca a Lacan, Copjec y Zizek para referirse a lo que denomina "el efecto retroactivo del nombrar", por medio del cual "es el nombre mismo, el significante, el que sostiene la identidad del objeto" (Laclau 2005: 133). Lo que la tradición psicoanalítica nos enseña es, en otras palabras, la imposibilidad de aprehender todas las implicaciones prospectivas y retrospectivas del acto de dar nombre, que siempre se sitúa en una relación al tiempo productiva y reproductiva en relación con el acto de dar vida, al tiempo que señala que un nombre propio es, por naturaleza, impropio: ni puede identificarse con la persona o con el lugar ni alcanza la totalidad de aquello que supuestamente denota. Eso es lo que, por otras palabras, pone en evidencia Cabo Aseguinolaza (2018: 9) cuando escribe que "los topónimos no son un mero detonante transparente para la asignación de coordenadas a un lugar" y también lo que explica que Gibson recurra tanto a la toponimia como a la etimología y a la razón poética para reforzar su hipótesis de que Lorca descansa en el parque homónimo, aunque sus restos no hayan sido encontrados todavía: "Estoy persuadido de que Lorca está en el parque que lleva su nombre, a dos pasos de la acequia de Aynadamar, construida por los árabes en el siglo XI para trasladar agua a Granada. La palabra significa Fuente de las Lágrimas. Toda una profecía (Ruiz Mantilla, 2018).

Ese resto que escapa a la nominación es asimismo el problema que se juega en la estela que proclama que "Lorca eran todos", haciendo evidente, pero también ocultando, la singularidad de cada uno de los cuerpos que conforman una multitud: en este caso, un ejército de muertos que todavía nos hablan. Las dimensiones biopolíticas del problema se acentúan si tenemos en cuenta la dificultad para decidir sobre la suerte de un muerto a quien su familia desea, por lo demás sin conseguirlo, proteger de la atención pública. Una posición en las antípodas de la sustentada por Gibson, que con motivo de la revisión de su investigación sobre el poeta — reeditada bajo el título El asesinato de García Lorca (2018) — , se pronunciaba al respecto en términos inequívocos: "El poeta representa a todos las víctimas del franquismo. A más de 100.000, que aún siguen en las cunetas. Es un símbolo universal, no pertenece a nadie" (Ruiz Mantilla 2018). En la afirmación de que el poeta "no pertenece a nadie" es fácil percibir ecos del ya citado "Rosalía é de todos", solo en apariencia antagónico. A ambos subyace un régimen poético y político que convierte el nombre de los poetas en un significante vacío al servicio, en este caso, de dos representaciones colectivas: un pueblo sin Estado, en el caso de Rosalía de Castro (la "suscripción nacional" y "gloria da súa patria" de la lápida funeraria de Bonaval remiten indudablemente al léxico político), y un Estado destituido por la fuerza, en el caso de Lorca. Los dos casos confirman, por lo tanto, la ubicuidad de la idea del Estado incluso en sujetos políticos situados en oposición a (o en la periferia de) un Estado real: esa Galicia de la que Rosalía de Castro afirmó que no tenía patria (como había dicho, contemporáneamente, Marx del proletariado), marginal entonces y ahora con respecto al centro del Estado, y esa República española perdida que vive sin embargo todavía en la obra de Lorca. Una vez más, la muerte de los poetas a quienes la sociedad concede, o las instituciones buscan conceder, un lugar de relevancia cultural es sin duda un lugar de quiebre de las distinciones socialmente operantes entre la vida y la obra o, si se prefiere - aunque no sea, en puridad, una oposición correlativa- de lo privado y lo público.

\section{La exhumación del poeta manco}

Pocos casos como el de Cervantes se prestan más a un análisis como el aquí propuesto. Su posición de honor en el canon del hispanismo trasciende la dimensión estrictamente literaria, hasta el punto de que su nombre se ha convertido en marca y metonimia de la cultura hispánica, entendida en un sentido a menudo militante. Así se deja ver, entre otros indicios, en asociaciones como la 
denominada Acción Cultural Miguel de Cervantes, aprobada por el Ministerio del Interior en el año 1983. La asociación nacía en Cataluña, vinculada a entidades como la Asociación por la Tolerancia o Profesores por el Bilingüismo, en clara respuesta a la ley de normalización linguiística aplicada por la Generalitat en los albores de la España autonómica. Pero el uso del nombre de Cervantes como soporte de la reivindicación de una hegemonía cultural de la lengua castellana traspasa las fronteras del Estado. Lo vemos con claridad en el hecho de que la Biblioteca Virtual Miguel de Cervantes, dependiente de la Fundación homónima, se presente en la página web como el mayor repositorio digital de contenidos en castellano y como un espacio de consagración -y, por lo tanto, de unificación cultural, bajo el marchamo de la sobredeterminación lingüística- de los escritores en los ámbitos español y latinoamericano.

Desde el punto de vista estrictamente histórico, es imposible reconocer una continuidad entre el proyecto literario y vital cervantino y los usos políticos y culturales a los que su figura ha venido dando lugar. Esta distancia se volvió clamorosa en el presunto acto de reparación histórica del que fue objeto la memoria de Cervantes con ocasión de su exhumación y posterior inhumación en la iglesia del convento de San Ildefonso y San Juan de la Mata, ubicada en el número 18 de la madrileña calle Lope de Vega Madrid. En un acto de innegable carácter institucional, al muerto se le rindieron honores militares por parte de los Regimientos del Ejército. Además de las Fuerzas Armadas, asistieron representantes de la Real Academia Española y Joaquín Martín Abad, el Vicario para la Vida Consagrada, como representante de la jerarquía eclesiástica (Gómez 2015). En un ejercicio de forzada continuidad histórica entre el pasado imperial y el presente, Ana Botella pudo proclamar, en un deje de familiaridad que no deja dudas sobre el tipo de relación que la política municipal deseaba entablar con el muerto: "Don Miguel, misión cumplida" (Rivas 2015). Aquel fue, de hecho, el último acto público de la alcaldesa, que eligió cerrar su mandato con un discurso en el que destacaba que la actuación política del Ayuntamiento permitía dar cumplimiento a la última voluntad del difunto. Una interpretación sin duda más osada que aquella que hace de la filología el cumplimiento de la última voluntad de un autor sobre su obra, en la línea de lo defendido por Francisco Rico (2015a) en uno de los artículos dedicados a las efemérides cervantinas ${ }^{20}$ : "Como filólogo, me importa, y llevo años en ello, recuperar el texto del Quijote (o de cualquier otro libro) de acuerdo con la última voluntad del autor. Como prójimo, opino que lo más justo es respetar en otros aspectos la que fue también su última voluntad".

El cervantista Rico fue, de hecho, uno de los pocos investigadores que se interrogó públicamente sobre la pertinencia de la exhumación y posterior inhumación de Cervantes $^{21}$, llamando de paso la atención sobre el clamoroso silencio en torno a Catalina de Salazar (Rico 2015a). Pues lo que ni el epitafio ni el monumento sufragados por la Real Academia Española reconocen es que la fosa

\footnotetext{
${ }^{20}$ Con posterioridad al centenario, Rico reunió los artículos dedicados a la efeméride en el volumen Anales cervantinos (2017).

${ }^{21}$ El documento de la inhumación es accesible en la página web del Ayuntamiento de Madrid: "Testimonio de la inhumación de los restos de Miguel de Cervantes Saavedra en la iglesia del convento de San Ildefonso, de Trinitarias Descalzas, de Madrid. Ayuntamiento de Madrid, 10 de junio de 2015": http://www.madrid.es/UnidadesDescentralizadas/ UDCMedios/noticias/2015/06Junio/11Jueves/NotasdePrensa/BotellaCervantes/ficheros/Acta\%20Inhumaci\%C3\%B3n.pdf.
} 
cervantina es una fosa común. Las evidencias de los investigadores encargados del proyecto de exhumación así lo concluyen: entre los restos que es posible identificar con los de Cervantes habría vestigios de al menos cinco niños, tal vez seis, y diez adultos (dos mujeres, seis probablemente hombres y dos de género indeterminado), entre los que se encontraría la mujer del escritor. A esta luz, adquiere un nuevo sentido la argumentación de Rico (2015a), que en su artículo insistía en que toda la iglesia debía de ser considerada tumba: "Creo que fue don Antonio Maura quien primero habló de la ‘tumba difusa' que es el convento de las Trinitarias. ¿Qué mejor tumba que todo un templo?’. Rico plantea el argumento en su primer artículo, inmediatamente posterior al hallazgo, y lo repite en la víspera de la misa que la RAE, bajo el epígrafe "solemne funeral por D. Miguel de Cervantes Saavedra y cuantos cultivaron las letras hispanas", le dedica cada año, poniendo de relieve la imbricación de las exhumaciones en la política municipal: "Después de la batalla por la alcaldía de Madrid que se ha reñido con los hipotéticos restos del novelista, es de esperar que la asistencia no se reduzca a la habitual de algunos académicos y dos o tres devotos (con una sola devota) sino que se abarrote el templo de la vieja calle de Cantarranas. Ello debiera convencer al municipio de que lo sensato es contribuir a que la iglesia de las Trinitarias se conserve primorosa, reconociéndola como lo que es, toda ella tumba de Cervantes (y despintándole las enaguas al Cristo), en vez de gastarse los cuartos en una urna con huesos surtidos" (Rico 2015b).

El hecho de que el lugar donde reposa el escritor más canónico de la literatura española sea una fosa común adquiere también resonancias singulares en términos de las políticas españolas del presente. Es la urna habitada por cuerpos y por objetos (restos de ropa y una moneda) lo que permite conectar a Cervantes con la suerte de los cuerpos todavía indistintamente enterrados en las cunetas y cuya memoria, en la mayoría de los casos, no ha sido ni reparada ni honrada por el Estado. En el mismo año 2014 en el que comenzó la aventura del desentierro cervantino, los investigadores que emprendían de nuevo la búsqueda del cuerpo de Lorca estaban siendo apoyados por miembros del equipo que participó en la exhumación de los restos de Cervantes. En este sentido, la ya mencionada participación del antropólogo forense Francisco Etxebarría, en la segunda fase de la investigación, es un hecho que trasciende la categoría de anécdota, al tiempo que permite mostrar la complejidad de procesos que, como el de la exhumación de cuerpos, están atravesados por múltiples objetivos y agencias (civiles, académicos, económicos, políticos), y en donde la investigación científica corre el riesgo de convertirse en un mero instrumento de los intereses de las instituciones públicas.

Resulta revelador, a este respecto, que para la relación del estudio científico de la exhumación cervantina debamos remitimos únicamente a la hemerografía. En efecto, los investigadores tuvieron que aceptar un pacto jurado de confidencialidad, que en la rueda de prensa que culminaba los trabajos de exhumación Etxeberría justifica aludiendo al objetivo de "evitar la dispersión informativa y unificar su emisión" (Fraguas y Manrique 2015). Según esta misma fuente, el origen de la búsqueda se remonta a enero de 2014, momento en el que Fernando Prado se propuso emprender un estudio geofísico en torno al convento para determinar la ubicación de los restos de Cervantes. Para ello cuenta con Luis Avial, georradarista también implicado en la exhumación de los restos de Lorca. Al parecer la investigación se retrasa por la necesidad de armonizar los intereses civiles y eclesiásticos: cabe 
recordar que el convento había sido objeto de cuatro desamortizaciones, la última de 1868, lo que sin duda habría de influir en la resistencia de las monjas trinitarias a facilitar los libros de registro del convento (Fraguas y Manrique 2015).

Lo notable del caso es la enorme disparidad entre el presupuesto con el que se dotó la fase geofísica del estudio (12.000 euros), que, una vez obtenidos los permisos del Ayuntamiento y del Arzobispado de Madrid, se prolongó durante diez meses, y los 102.000 euros con los que, desde enero a febrero de 2015, contó el equipo para llevar a cabo las restantes investigaciones (Fraguas y Manrique 2015). Se trataba, por lo demás, de la parte fundamental de la investigación, que comprendía tanto el examen científico resultante de las exhumaciones, liderado por Exteberría, como la investigación histórico-archivística, coordinada por el doctor en Historia y bibliotecario municipal Francisco José Marín Perellón. Por razones presupuestarias, y en sentido contrario a lo que parecería dictar la metodología de un trabajo de semejante envergadura, el análisis histórico hubo de esperar a la segunda fase, de tan solo mes y medio de duración. El alcance temporal resulta casi inaudito dada la dispersión del archivo de referencia para el caso: Archivo Histórico Nacional, Archivo Diocesano, Biblioteca Nacional o Archivo de los duques de Medinaceli, sin contar con el examen de los libros de registro de la parroquia de San Sebastián y los documentos albergados por las trinitarias (Fraguas y Manrique 2015).

Esta breve relación de hechos pone de relieve hasta qué punto la investigación en España está sujeta a los ritmos, generalmente cortoplacistas, de la gestión política. En el caso de la exhumaciones de los escritores convertidos por la tradición en glorias literarias de alcance local o nacional, estas decisiones no parecen ni siquiera respetar a los muertos más que para sacar de ellos la oportuna dosis de réditos políticos. En términos de la justificación de un gasto público resulta difícil de explicar que más de tres años después de la intervención el horario de visitas al monumento siga supeditado al horario de misas del convento. Tampoco se ha avanzado en el proyecto de creación de un centro cultural dedicado al Siglo de Oro, iniciativa surgida a propuesta del entonces portavoz del PSOE en el Ayuntamiento, Jaime Lissavetzky, junto con la responsable de Cultura, Ana d'Atri (Fraguas y Manrique 2015). Ni siquiera se ha activado la posibilidad inicialmente explorada de favorecer el acceso al monumento por la calle de Las Huertas, promoviendo un itinerario turístico en torno al túmulo, de acuerdo con la lógica, cada vez más generalizada en las ciudades europeas de entender y re-capitalizar el patrimonio cultural como bien de interés turístico.

Ya a propósito de Lorca observamos la regulación de las políticas del nombre de los poetas por parte de los poderes públicos. En el caso de Cervantes, la piedra ni siquiera guarda la memoria de aquello que empareda. La Real Academia Española, que se encargó de sufragar el monumento ${ }^{22}$, escogió como epitafio un fragmento del prólogo de Los trabajos de Persiles y Sigismunda (1616), debido sin duda a su contenido (más reticente de lo que podría parecer en una primera lectura) y al hecho de que el autor lo terminó muy poco antes de su muerte: "Yace aquí Miguel de Cervantes

\footnotetext{
${ }^{22}$ El portal de la institución recogía la noticia bajo el título "Un monumento funerario recuerda desde hoy a Cervantes en las Trinitarias" (RAE, 11 de junio de 2015), en http://www.rae.es/noticias/un-monumento-funerario-recuerda-desde-hoycervantes-en-las-trinitarias (último acceso, 22-5-208).
} 
Saavedra (1547-1616). 'El tiempo es breve / las ansias crecen / las esperanzas menguan / y, con todo esto / llevo la vida sobre el deseo / que tengo de vivir"'. Pero en el mismo gesto destinado a honrar la memoria del poeta, las instituciones esculpen en la piedra políticas de la singularización nominal del genio y condenan al olvido incluso los nombres de quienes, como su mujer, fueron relevantes en su vida. Por más que los versos elegidos en la placa conmemorativa fuesen los del Persiles, cualquier lector de Cervantes haría bien en evocar, a propósito de su denominado "reentierro jurídico" (Fraguas 2015), la humorada final del "Soneto al túmulo de Felipe II en Sevilla": "Y luego, in continente, caló el chapeo, requirió la espada, miró al soslayo, fuese y no hubo nada". Con el tenue pretexto de que el muerto había sido soldado de España, a un humilde recaudador de impuestos que conoció la cárcel y que antes de morir "mandó dos misas de alma" (Rico 2015) se le rendían honores militares tras el segundo homenaje público que se le dedicaba el mismo año (Fraguas 2015, Gómez 2015, Rivas 2015). Homenajes en los que la Iglesia desempeñaba un notable papel, en una nueva muestra del peso de las instituciones eclesiásticas en la vida española. Pero también en una prueba inequívoca de hasta qué punto el patrimonio cultural está sometido a decisiones no siempre rigurosamente motivadas y de las que raras veces se rinde cuentas a los ciudadanos.

En este contexto de sujeción de la memoria de los poetas a los intereses económicos y políticos, cabría preguntarse cuál debería ser el papel de los estudios literarios. En los artículos mencionados, Rico se permitía invocar la necesidad de una filología atenta a la restauración del sentido de los textos, práctica que, en cualquier caso, encontró menos eco mediático que la recuperación del cuerpo del escritor en las exequias cervantinas. Cabría recordar el hecho, aducido por el propio Rico (2015b), de que según el documento exhumado por Blas Nasarre en 1749, el 23 de abril no sería la efeméride de la muerte de Cervantes, sino la de su entierro. Dado que ni los poderes políticos ni los económicos tienen entre sus atribuciones la de velar por el establecimiento de discursos y prácticas de continuidad entre el patrimonio cultural y sus usos en el espacio público, cabría preguntarse si los investigadores literarios no tienen nada qué decir al respecto. No parece casual que no hubiese ningún filólogo entre los líderes del proyecto interdisciplinar de exhumación cervantina y que, excepto en casos puntuales como el de la intervención de Fernández Mosquera en la exhumación de Quevedo en Villanueva de los Infantes, el saber literario aparezca excluido automáticamente de estas operaciones de rescate de los cuerpos ${ }^{23}$. Y ello aun cuando el principal problema suscitado por las tumbas de los poetas muertos probablemente no pueda ni deba dejar fuera el análisis de su producción literaria, que en cierto sentido no sería descabellado leer como su última voluntad legítima. En este sentido, el emplazamiento del cuerpo en un lugar, y no en otro, sería, en lo fundamental, una cuestión de naturaleza hermenéutica: ¿cómo interpretar su voluntad de estar, o de no estar allí, a la luz de su obra? O, si lo preferimos, ¿cómo honrar, sin manipulaciones ni desvíos oportunistas, su memoria?

\footnotetext{
${ }^{23}$ A propósito de la santificación de los escritores ya notada en el caso de Rosalía de Castro, véase el arranque del artículo de Fernández Mosquera (2004: 7) en donde Tarsia evoca el motivo del cuerpo incorrupto de Quevedo.
} 


\section{Algunas conclusiones}

A lo largo del siglo XX, la relación de los escritores con los poderes públicos ha dado lugar a escenas tan recordadas como la del poeta Robert Frost, invitado a leer un poema a la sesión de investidura de John Fitzgerald Kennedy como presidente de los Estados Unidos. El autor de "El camino no elegido", que suele interpretarse como una contemporánea oda a la vida retirada, no dudó en terminar la composición escrita ad hoc para la investidura con el siguiente dístico: "Una edad de oro de la poesía y el poder / de la que este mediodía es el comienzo". Pero la naturaleza tenía otros planes. Aquel 20 de enero de 1961 el viento que se llevó las hojas, la luz deslumbrante en la nieve o incluso la vista cansada del escritor - siempre son múltiples las variantes de un relato biográfico- le impidió a Frost leer el poema que había compuesto (Hart 2017: 365-370). Fue, en suma, el azar el que forzó al escritor a reemplazar un monumento literario ocasional por el único texto que se sabía de memoria. Un margen de maniobra del que no dispone ningún poeta muerto y enterrado, especialmente cuando su memoria es acechada por la lógica monumental que se ha hecho preceptiva en los usos del pasado literario. La anécdota referida muestra que la relación entre literatura y Estado resulta siempre insidiosa a la hora de pensar en la vida y en la obra de los poetas vivos, pero a lo largo de estas líneas hemos podido verificar que se vuelve todavía más problemática cuando alcanza a la gestión pública de sus tumbas. Sobre todo porque a quién debe corresponder esta gestión no es un problema resuelto y, por difícil que parezca, ni siquiera generalmente planteado como problema.

Los tres casos de estudio presentados sumariamente en el artículo confirman, por lo demás, una sospecha. Ni el desplazamiento de la tumba de Rosalía, ni la búsqueda del cuerpo de Lorca, ni siquiera el reentierro de Cervantes fueron presentados formalmente ante la sociedad como asuntos de Estado, pero sería ilusorio pensar que el Estado no ha comparecido en ellos, incluso cuando en apariencia procure antes cancelar ciertas operaciones que ampararlas, como a menudo sucede en la exhumación de las fosas de la Guerra Civil. Lo ilustra el carácter en buena medida paradójico del "entierro jurídico" de Cervantes. Los estamentos militar, civil y eclesiástico están representados a través de sus máximas autoridades, pero hay una resistencia explícita a presentarlo como un funeral de Estado. Preguntada explícitamente por la cuestión, la alcaldesa Ana Botella dice que no es asunto de su competencia (Fraguas y Manrique 2015) y Francisco Rico (2015b) se encarga de recordar que la RAE es una institución de carácter privado, aun cuando matice que su "relevancia pública, sin embargo, justifica que el gobierno intervenga en asuntos como la aprobación de sus estatutos". Sin duda las estelas funerarias llamadas a honrar a Cervantes, Lorca y Rosalía — pendientes de una lectura visual menos sumaria de la que aquí hemos emprendido- encarnan materialmente el alcance de una memoria literaria pública, pues obedecen a una lógica monumental del Estado que elige, para los sepulcros, textos y materiales llamados a proclamar el poder de dar nombre.

No hace falta insistir en que todos estos casos muestran, en mayor o menor grado, una actuación indirecta o in absentia del Estado, en modos de delegación cuyo alcance y atribuciones, especialmente en estructuras administrativas complejas y en crisis, no siempre son ni eficaces ni transparentes. Pero en su función última, esa estructura reticular integrada por nodos de autonomías, ayuntamientos, 
asociaciones, fundaciones privadas o academias que gozan de financiación pública, está asegurando la posibilidad de interpretar retroactivamente cuestiones tan inaccesibles al conocimiento como la última voluntad de Cervantes. En otras palabras, acaso una de las funciones del Estado en el ámbito cultural sea fijar las condiciones de posibilidad de afirmaciones como "Rosalía é de todos" o "Lorca no es de nadie". Ese poder de abstracción del Estado (de cualquier Estado: del que todavía no existe, del que es proyectado como ideal o del que ha sido derrocado) es también el que explica el desplazamiento de lo íntimo a lo público en la modernidad, tan importante en la emergencia de discursos como el autobiográfico o el epistolar. No por casualidad ya hace años Jacques Rancière (1985) definía el poder de abstracción de la literatura — cuyo proceso de constitución moderna es, por muchos conceptos, paralelo al de la constitución del Estado - a partir del tropo de una carta escrita por nadie y dirigida a nadie.

Dada la proverbial conexión del discurso lírico con la intimidad, estas funciones de abstracción y exterioridad garantizadas por el espacio público parecerían más difíciles de fijar socialmente en el tratamiento de la memoria de los poetas. Sin embargo, tal y como hemos visto, en la práctica este ámbito resulta ser uno de los más privilegiados en la acción institucional. Acaso porque, de acuerdo con las políticas toponímico-topográficas y antroponímicas, el poder de nombrar del Estado sabe reconocer, capitalizar e instrumentalizar el valor afectivo de la poesía y de los poetas. Pero en la medida en que son justamente los poderes de autonomía y abstracción, tanto de la literatura como del Estado, los que parecen haber entrado progresivamente en crisis (crisis de la que constituyen indicios poderosos la misma omnipresencia de las comunidades unidas por lazos mnemónicos, así como la preocupación por el carácter póstumo de los legados culturales), tal vez sea posible reconocer o, en su caso, construir un espacio de contestación en relación con el uso público de la memoria literaria. Podría resulta útil, a este respecto, retomar un concepto introducido por Ricardo Piglia a propósito de su concepción de la Universidad como un "espacio contra-público" (Piglia 2015: 193), como ámbito desde el que conjurar la tendencia al hecho de que hoy en día "todo el mundo discute los mismos problemas, desde posiciones y estilos distintos quizás, pero el orden del día del debate público lo deciden los medios y el Estado" (193), especialmente en países "cruzados por los procesos de internacionalización y de concentración de la industria cultural y de ciertas tendencias muy agudas a la endogamia y al provincianismo (son siempre los mismos los que hablan de lo mismo)" (194) ${ }^{24}$.

Creo que no se trata tanto de defender la autonomía del espacio universitario con respecto a los poderes políticos y económicos —una autonomía, por lo demás, cada vez más debilitada en el Estado español- como de postular la necesidad de un lugar desde el que pensar problemas como los enunciados al margen de las demandas de las instituciones públicas, de las fundaciones legatarias y/o empresas interesadas en la acción cultural o de los intereses particulares de los herederos de la memoria

\footnotetext{
${ }^{24}$ Piglia (2015: 193) reconoce el carácter paradójico de haber encontrado en las universidades americanas "el mismo tipo de autonomía con respecto a las demandas y a los debates públicos que encontraba en las culturas alternativas en las que me formé en los años 60, donde nosotros discutíamos una serie de cuestiones antagónicas a la discusión de los medios y estábamos totalmente ajenos a lo que podríamos llamar la institución y el establishment literario y al orden del día en la discusión pública".
} 
de los escritores. En este sentido, se hace apremiante redefinir el alcance de los estudios literarios en general, y de la teoría crítica en particular, conectando este necesario proceso de renovación teórica y metodológica en torno a la memoria literaria con la posibilidad de activar discursos y prácticas culturales vigilantes ante las distorsiones de las que es objeto la imagen de los escritores en el espacio público. Como hemos podido constatar, salvo excepciones, la investigación literaria brilla por su ausencia en las exhumaciones de los cuerpos de los poetas, situadas literalmente en las manos de la antropología forense, de la arqueología o de la historia. Una posible rearticulación de los estudios literarios y culturales, en sus conexiones con la teoría de la memoria, acaso implique reconocer que la contribución del análisis literario no es únicamente ocuparse del corpus de los poetas sino de sus cuerpos muertos y enterrados, sí, pero más vivos que nunca a juzgar por las controversias que su uso público sigue desatando y que, hasta ahora, no ha sido por desgracia objeto de atención sistemática. Se trata de una tarea tan comprometida y desafiante como la pregunta, jamás concluida pero en estos tiempos particularmente crítica, sobre la función social de la literatura y de los estudios que tratan, con mayor o menor fundamento, de responder por ella en el espacio público.

\section{Bibliografía}

Álvarez RuIz DE OJEDA, V. (1997): "Un importante documento para a biografía de Rosalía de Castro", Grial, 136, pp. 479-501.

(1999): "Sobre as orixes de Rosalía de Castro: a inclusa de Santiago de Compostela e o caso de Josefa Laureana de Castro", A Trabe de Ouro, 39, pp. 325-351.

- (2000): "Documento para a biografía de Rosalía de Castro, testamento de José Martínez Viojo, presbítero", Grial, 146, pp. 169-172.

BARREIRo FERnÁNDEZ, X. M. (2012): Murguía. Vigo, Galaxia.

BILlig, M. (1995): Banal Nationalism. New York, Sage.

Bourdieu, P. (1995): Las reglas del arte. Génesis y estructura del campo literario. Barcelona, Anagrama.

CABALlERO, M. (2011): Las trece últimas horas en la vida de García Lorca. Madrid, La Esfera de los Libros.

Cabo Aseguinolaza, F. (2011): "Exotopía y emergencia. Sobre La hija del mar de Rosalía de Castro", en A. ApolináReIo Lourenço y O. M. Silvestre, eds., Literatura, espaço, cartografias. Coimbra, Centro de Literatura Portuguesa (Universidade de Coimbra), pp. 17-38. (2018): "Ficción y lugar: los topónimos desde la teoría de la literatura" (en prensa).

CAmacho, J. (2016a): "La tercera búsqueda de Lorca", El Periódico, 17 de abril de 2016, en https://www.elperiodico.com/es/ocio-y-cultura/20160417/garcia-lorca-fosa-penon-colorado$\underline{5060380}$ (última consulta, 17-5-2016).

— (2016b): “¿Dónde está Federico?”, El Periódico, 13 de julio de 2016, en https://www.elperiodico.com/es/ocio-y-cultura/20160813/garcia-lorca-restos-mortales-penondel-colorado-5319407 (última consulta, 22-5-2018). 
Carballo CAlero, R. (1963): Historia da literatura galega contemporánea. Vigo, Galaxia.

CLÚA, I. (2016): Cuerpos de escándalo. Celebridad femenina en el siglo XIX. Barcelona, Icaria.

Cortés, V. (2008): “Enfrentamiento entre dos docentes”, El País, 16 de noviembre de 2018, en https://elpais.com/diario/2008/11/16/cultura/1226790005_850215.html (última consulta, 25-52018).

Delgado, M. M. (2008): Federico García Lorca. Londres, Routledge.

Doval, M. (2014): "Novos datos para a biografía de Rosalía de Castro", Sermos Galiza, 18 de septiembre de 2014, en http://www.sermosgaliza.gal/opinion/marga-do-val/novos-datosbiografia-rosalia-castro/20140918075426030665.html (última consulta, 15-12-2017).

Dovic, M. - Helgason, J. K. (2016): National Poets, Cultural Saints: Canonization and Commemorative Cults of Writers in Europe. Leiden, Brill.

FERnÁndeZ Mosquera, S. (2004): “Quevedo y los santos”, Criticón, 92, pp. 7-37.

Fraguas, R. (2015): “Cervantes, reenterrado solemnemente”, El País, 11 de junio de 2015, en https://elpais.com/ccaa/2015/06/11/madrid/1434030270_695768.html (última consulta, 22-52018).

Fraguas, R. - MAnRiQue, W. (2015): “Los restos de Cervantes: preguntas y respuestas”, El País, Cultura, 15 de marzo de 2015, en https://elpais.com/cultura/2015/03/17/actualidad/ 1426582091_425701.html (última consulta, 19-5-2018).

FreGe, G. (1998): Ensayos de semántica y filosofía de la lógica. Madrid, Tecnos.

Fuentes Rios, A. (2018): "Victoriano García Martí et les origines du tourisme littéraire à SaintJacques-de-Compostelle: Un enjeu idéologique et ethnographique", Téoros. Revue de Recherche en Tourisme, 37/1, en https://journals.openedition.org/teoros/3204 (última consulta, 25-5-2018).

GIBSON, I. (1971): La muerte de Federico García Lorca y la represión nacionalista de Granada. Madrid, Ruedo Ibérico.

- (2018): El asesinato de García Lorca. Barcelona, Ediciones B.

GómEZ, P. (2015): “Las Trinitarias celebran el último funeral de Cervantes”, La Razón, 11 de junio de 2015, en http://www.larazon.es/local/madrid/las-trinitarias-celebran-el-ultimo-funeral-decervantes-NE9969539 (última consulta, 25-5-2018).

GonZÁlez Liste, A. (2017): "Rosalía é de todos”, La Opinión, 2 de febrero de 2017, en http://www.laopinioncoruna.es/sociedad/2017/02/24/rosalia-e/1155809.html (última consulta, 22-5-2018).

Halbwachs, M. (1992): On Collective Memory. Chicago, University of Chicago Press.

HART, H. (2017): The Life of Robert Frost: A Critical Biography. Oxford, Willey \& Blakcwell.

KRIPKE, S. A. (1980): Naming and Necessity. Oxford, Basil Blackwell.

LABANYI, J. (2002): "Introduction: Engaging with Ghosts; or, Theorizing Culture in Modern Spain", en Constructing Identity in Contemporary Spain: Theoretical Debates and Cultural Practice. Oxford, Oxford University Press, 2002, pp. 1-14.

(2007): "Memory and Modernity in Democratic Spain: The Difficulty of Coming to Terms with the Spanish Civil War", Poetics Today, 28/1, pp. 89-116. 
LABRADOR MÉNDEZ, G. (2014): “The cannibal wave: the cultural logic of Spain's temporality of crisis (revolution, biopolitics, hunger and memory)", Journal of Spanish Cultural Studies, 15, pp. 241271.

(2017): Culpables por la literatura. maginación política y contracultura en la transición española (1968-1986). Madrid, AKAL.

LAClAU, E. (2005): La razón populista. Buenos Aires, FCE.

LAMA, M. X. (2017): Rosalía de Castro. Cantos de independencia e liberdade. Vigo, Galaxia.

LóPez, U. (2018): "Padrón, Ames y Brión convierten en ruta turística los escenarios de la vida de Rosalía de Castro", La Voz de Galicia, 20 de enero de 2018, en https://www.lavozdegalicia.es/ noticia/santiago/brion/2018/01/20/padron-ames-brion-convierten-ruta-turistica-escenarios-vidarosalia-castro/0003_201801S20C6991.htm (última consulta, 18-5-2018).

Martín-Arroyo, J. (2015): "Laura García Lorca denuncia al secretario de la fundación del poeta", El País, 28 de junio de 2015, en https://elpais.com/cultura/2015/06/28/actualidad/1435509949 455057.html (última consulta, 25-5-2018).

MÉndez Ferrín, X. L. (2007a): "Pómulos famosos: pé de foto”, El Faro de Vigo, 17 de noviembre de 2007.

_ (2007b): "A novela familiar de Rosalía de Castro", El Faro de Vigo, 24 de noviembre de 2007. Molina Fajardo, E. (1983): Los últimos días de Federico García Lorca. Barcelona, Plaza \& Janés. Murguía, M. (1885): Los precursores. A Coruña, La Voz de Galicia.

NoRA, P. (1989): “Between Memory and History: Les Lieux de Mémoire”, Representations, 26, pp. $7-25$.

OsORIO, M. (2011): Miedo, olvido y fantasía: crónica de la investigación de Agustín Penón sobre Federico García Lorca. Granada, Comares.

Piglia, R. (2015): “Conversación en Princeton”, en Arcadio DíAZ QuiÑones y Paul FiRBAS, eds., $L a$ forma inicial. Conversaciones en Princeton. Buenos Aires, Eterna Cadencia, pp. 189-248.

PASTORIZA, F. R. (2016): “García Lorca: 80 años de enigma”, en https://periodistas-es.com/garcialorca-80-anos-enigma-74870 (última consulta, 22-5-2018).

PoniatowsKa, E. (2018): "México. La única protesta estudiantil que terminó en catástrofe". Suplemento Babelia. Especial Mayo del 68: El mes que cambió un siglo, 5 de mayo de 2018, p. 10.

Pozo Felguera, G. (2009): Lorca, el último paseo. Claves para entender el asesinato del poeta. Almed, Granada.

RANCIERE, J. (1985): La parole muette: essai sur les contradictions de la littérature. París, Hachette.

REgUeIRA, M. (2017): “Aeropuerto Rosalía de Castro”, O porto dos escravos, en https://marioregueira. gal/es/2017/02/aeropuerto-rosalia-de-castro/ (última consulta, 25-5-2018).

RESINA, J. (2000): "Short of Memory: the Reclamation of the Past Since the Spanish Transition to Democracy", en J. RESINA, ed., Disremembering the Dictatorship: The Politics of Memory in the Spanish Transition to Democracy. Amsterdam, Rodopi, pp. 83-126. 
RiCO, F. (2015a): "Las tumbas de Cervantes”, El País, 18 de marzo de 2015, en https://elpais.com/ cultura/2015/03/17/actualidad/1426621148_602804.html (última consulta, 18-3-2018).

— (2015b): "Muerte, sepultura y purgatorio", El País, 22 de abril de 2015, en https://elpais.com/ cultura/2015/04/21/actualidad/1429637827_253444.html (última consulta, 19-5-2018).

- (2017): Anales cervantinos. Barcelona, Arpa.

RoDRÍGUEZ, F. (2011): Rosalía de Castro, estranxeira na súa patria. (A persoa e a obra de onte a hoxe. A Coruña, Asociación Socio-Pedagóxica Galega.

(2017): “A propósito dunha biografía de Rosalía de Castro”, Sermos Galiza, 24 de abril de 2017, en https://www.sermosgaliza.gal/opinion/francisco-rodriguez/proposito-dunha-biografia-rosaliacastro/20170421192508056808.html (última consulta, 21-5-2018).

RIVAS, T. G. (2015): "Madrid ya tiene su monumento literario a Cervantes". $A B C, 11$ de junio de 2015, en http://www.abc.es/madrid/20150611/abci-miguel-mision-cumplida-madrid-201506111158. html (última consulta, 19-5-2018).

RoCA DE TOGORES, M. (1870): La sepultura de Miguel de Cervantes: memoria escrita por encargo de la Academia Española y leída a la misma por su director el Marqués de Molins. Madrid, Imprenta y Estereotipia de M. Rivadeneyra.

Ruiz Mantilla, J. (2018): "Ian Gibson: «Estoy convencido de que Lorca está cerca de la fuente de Aynadamar»", El País, 7 de abril de 2018, en https://elpais.com/cultura/2018/04/05/actualidad/ 1522955163_385207.html (última consulta, 25-5-2018).

RUSSELL, B. (1910): "Knowledge by acquaintance and knowledge by description", en AA. VV., Proceedings of the Aristotelian Society, XI, pp. 108-128.

SALGado, D. (2010): "La pelea por el panteón”, El País, 27 de junio de 2010, en https://elpais.com/ diario/2010/06/27/galicia/1277633897_850215.html (última consulta, 19-5-2018).

VENTURA, L. (2015): "La muerte del poeta: nuevas hipótesis tras los restos de García Lorca”, La Nación, 5 de abril de 2015, en https://www.lanacion.com.ar/1781791-la-muerte-del-poetanuevas-hipotesis-tras-los-restos-de-garcia-lorca (última consulta, 17-5-2018).

Verdery, K. (1999): The Political Lives of Dead Bodies. Reburial and Postsocialist Change. New York, Columbia University Press.

VILA-SAN JuAn, J. L. (1977): García Lorca, asesinado. Toda la verdad. Barcelona, Planeta. 